\title{
Turismo nas praias do Farol: o olhar da comunidade sobre as práticas de hospitalidade
}

\section{Tourism in the beaches of the 'Farol': the community's view on the practices of hospitality}

\section{Turismo en las playas del 'Farol': la mirada de la comunidad sobre las prácticas de hospitalidad}

\author{
Renan de Lima da Silva ${ }^{1}$ \\ Maria Luiza Cardinale Baptista ${ }^{2}$
}

\section{RESUMO:}

O presente texto apresenta resultados sobre o turismo nas Praias do Farol, analisado a partir do olhar da comunidade, sobre as relações estabelecidas na atividade. A pesquisa teve como objetivos caracterizar as práticas turísticas nas Praias do Farol; descrever as relações estabelecidas entre os turistas e a comunidade; e observar e discutir os eventuais desdobramentos dessas relações e o turismo da localidade. Trata-se de estudo transdisciplinar, envolvendo as áreas: Turismo, Hospitalidade, Comunicação e Antropologia. A orientação metodológica é qualitativa, de cunho exploratório, com o desenvolvimento de revisão bibliográfica, observação participante com caderno e diário de campo e entrevistas abertas, gravadas e transcritas.Tem-se um panorama sobre as desterritoralizações da pesquisa, pensadas a partir de Baptista (2013); o turismo como manifestação cultural, entendido a partir de Geertz (1989); a característica das práticas turísticas das Praias do Farol, dividindo sazonalmente, segundo Arantes e Santos (2010); o espaço com a pesca e perpassado por características do estilo de vida do surf. Todos esses aspectos foram demonstrados a partir da descrição do turismo e da hospitalidade, segundo o olhar da comunidade. Estão associados aos desdobramentos das relações estabelecidas nas práticas

\footnotetext{
${ }^{1}$ Técnologo em Gestão de Turismo pela Universidade Federal do Pampa (UNIPAMPA) e Mestre em Turismo pela Universidade de Caxias do Sul (UCS). Professor substituto do curso de Tecnologia em Gestão de Turismo e Produção e Política cultural da Universidade Federal do Pampa (UNIPAMPA), Pesquisador do Amorcomtur! Grupo de Estudos em Comunicação, Turismo, Amorosidade e Autopoiese (UCS-CNPq). Email: renan.turismo@gmail.com

${ }^{2}$ Possui graduação em Jornalismo Gráfico e Audiovisual pela Universidade Federal do Rio Grande do Sul (1986), mestrado (1995) e doutorado em Ciências da Comunicação, pela Universidade de São Paulo (2000). Atualmente é professora e pesquisadora do Programa de Pós-graduação em Turismo e Hospitalidade e do Curso de Comunicação Social da Universidade de Caxias do Sul (UCS), Pesquisadoralíder do Amorcomtur! Grupo de Estudos em Comunicação, Turismo, Amorosidade e Autopoiese (UCSCNPq). Email: $\underline{\text { malu@ pazza.com.br }}$
} 
turísticas, tendo como marca o fato de que o 'localismo' do surfe e a hospitalidade, baseada nas trocas de Marcel Mauss (2002), são fatores que ajudam na preservação dessa cultura.

Palavras-chave: Turismo. Cultura. Hospitalidade. Surfe. Subjetividade.

\begin{abstract}
:
This dissertation is about tourism in Farol Beaches, viewed from the community look on the relations established in the activity. Aims to characterize the tourist practices on the Farol beaches; describe the relations between tourists and the community; and observe and discuss the possible consequences of these relationships in the locality tourism. This is an interdisciplinary study involving the areas Tourism, Hospitality, Communication and Anthropology. The methodological guidance is qualitative, exploratory, with the development of a literature review, participant observation with notebook and field diary and open interviews recorded and transcribed. In terms of results, there is an overview of the deterritorialization in the research, thought from the Baptist (2013), tourism as cultural expression, understood from Geertz (1989), characteristic of tourist practices of the Farol Beaches, dividing seasonally, according to Arantes and Santos (2010), the area with fishing and permeated by characteristics of the surf lifestyle. All these aspects have been demonstrated from the description of tourism and hospitality, according to the community look, fears and aspirations with those practices. The survey also, the developments of the relations established in tourist practices, with the marks the fact that the 'localism' surf and hospitality based on exchanges of Marcel Mauss (2002) are factors that help in preserving this culture, if we think from Castrogiovanni (2003), Barretto (2003) and Krippendorf (2000).
\end{abstract}

Keywords: Tourism; Culture; Beaches of Farol de Santa Marta; Hospitality; Surf; Subjectivity.

\title{
RESUMEN:
}

Este trabajo presenta los resultados sobre el turismo en la playa del faro, visto desde el aspecto de la comunidad en las relaciones que se establecen en la actividad. El objetivo del estudio fue caracterizar las prácticas turísticas en Faro Playas; describir las relaciones entre los turistas y la comunidad; y observar y analizar las posibles consecuencias de estas relaciones y el turismo de la ciudad. Es estudio interdisciplinario que involucra áreas: turismo, la hostelería, la comunicación y la antropología. La orientación metodológica es cualitativa, naturaleza exploratoria, con el desarrollo de la revisión de la literatura, la observación participante con el cuaderno y diario y entrevistas abiertas, grabado y transcritas.Tem es una visión general de la investigación desterritoralizações, pensado desde Baptista ( 2013); turismo como manifestación cultural entenderse a partir de Geertz (1989); las prácticas turísticos característicos de la playa del faro, dividiendo estacionalidad, de acuerdo Arantes y Santos (2010); espacio con la pesca y permeado por las características del estilo de vida del surf. Todos estos aspectos se han demostrado a partir de la descripción del turismo y la hostelería, de acuerdo con el aspecto de la comunidad. Están vinculados a la evolución de las relaciones que se establecen en las prácticas de turismo, con las marcas del hecho de que las olas "localismo" y la hospitalidad, basado en el intercambio de Marcel Mauss (2002), son factores que ayudan a preservar esta cultura. 
Palabras clave: Turismo. Cultura. Hospitalidad. Surfing. Subjetividad.

\section{Introdução}

O objeto de estudo deste trabalho que são as Praias do Farol $1^{3}$ de Santa Marta em Laguna SC e sua compreensão a partir das relações estabelecidas no local, segundo o olhar da comunidade.

A pesquisa resultou de um processo de descoberta empírica, que tem como marco o tempo em que vivi no Rio de Janeiro, onde estive até 2009. Naquela época, percebi que os turistas que chegavam à cidade, em busca de praticar esportes de aventura, se preocupavam em manter o ambiente limpo, contribuindo para a sua preservação. Eles compreendiam que necessitavam de interação com a comunidade para minimizar os riscos da atividade de aventura e a desestabilidade causada pela desterritorialização na sua prática, além de, é claro, consumirem produtos locais, deixando valores também econômicos, como registros de sua presença.

Acredito que o desenvolvimento do que está sendo aqui estudado se dá na interação. Assim, no contraponto com o outro se estabelecem as fronteiras e as culturas que resultam do jogo de aproximação e diferenciação. Nestas circunstâncias, a pesquisa aflorou.

Tais pensamentos são desenvolvidos no processo de construção de mim mesmo, como pesquisador, a partir de minha desconstrução/desterritorialização, em contato tanto com a pesquisa quanto com os aspectos interativos que ela me proporcionou.

Sendo assim, me questionei sobre qual orientação metodológica de pesquisa me permitiria captar à percepção sobre as relações estabelecidas a partir do olhar da comunidade. Optei por um trabalho qualitativo, com orientação da Antropologia, pautada por técnicas etnográficas, como observação participante e descrição da atividade no local,. Tais técnicas e metodologias escolhida me levaram a trabalhar com a perspectiva de James Clifford 2002, em que o mesmo defende sua ideia sobre a escrita etnográfica e a experiência relacionada a esse tipo de pesquisa, segundo o autor, nesse tipo de pesquisa, o que se deve trabalhar, através de uma

\footnotetext{
${ }^{3}$ Compreendo, ao longo de todo o trabalho, o significado que a própria comunidade local dá para suas praias. Essas são, como eles definem, a extensão do quintal de suas casas; portanto, o que aqui tratarei como as Praias do Farol é referendado a mim durante as entrevistas, como sendo a Prainha, Praia do Cardoso e Praia da Cigana.
} 
vigilância epstemológica intensa, é a percepção do autor como participante, causa e efeito do processo de pesquisa em um determinado momento em um determinado estudo.

A partir do dito anteriormente, a pesquisa aqui apresentada, de forma nenhuma leva em consideração um estudo especifico em uma situação e contextualização especifica, tanto de localidade como de personagens de pesquisa, não como molde e sim como amostra de possibilidade, portanto não trato aqui de uma construção ampla e sim de um microcaso de um todo, bem como o microcosmo proposto por Baptista (2014). Dito isso, gostaria de justificar que com base nas teorias metodológicas aqui propostas e trabalhadas, a escrita em primeira pessoa se demonstrou como a mais correta em nível ético e também em relação com a honestidade na produção dessa pesquisa, além de mais próxima com as suas propostas teórico metodológicas.

Sendo assim, o trabalho que se apresenta foi construído seguindo orientações etnográficas da escrita antropológica, segundo o entendimento de escrita contemporânea, corroborado pelo estudo de Peirano (1995), Eckert e Rocha (2008) . Em termos teóricos, este estudo foi produzido com base em teorizações de turismo, turismo de massa, turismo e cultura, e turismo como cultura, bem como apresenta referenciais ligados às teorias de subjetividade, em especial para a abordagem de desterritorialização em consideração a visitantes e visitados, com um olhar mais social sobre essas perspectivas de interação. Esses pressupostos teóricos e metodológicos foram escolhidos para estudar as implicações da temática em uma localidade. Assim, foi possível definir o objeto de estudo, a partir de questionamentos sobre as relações estabelecidas com o turismo, em um determinado ambiente, privilegiando a forma como olhar para tal relação, num recorte específico, e dando uma interpretação qualitativa a essa relação, considerando-a a partir da comunidade.

O que se segue é uma percepção de que, desde sempre, estive em constante movimento, assim como as ondas do mar. Nesse sentido, entendo que a experiência de surfar produz uma subjetividade que se faz presente na maneira de compreender o turismo e a pesquisa, nos moldes aqui trabalhados. Tudo isso sinaliza para a perspectiva de que, a partir desses, a viagem, a pesquisa, o turismo e, principalmente, a onda no surfe fazem parte da minha desconstrução/desterritorialização e reconstrução/reterritorialização. Assim, justamente como ondas transdisciplinares com o turismo, construí essa pesquisa, bem como posso dizer que, subjetivamente, ela me desterritorializou, ou seja, me descontruiu, e reterritorializou ou me reconstruiu novamente. 


\section{Apresentação do local de pesquisa}

O território do campo de pesquisa apresentou-se, para mim, em dois momentos, de duas formas diferentes. Primeiro, tornou-se meu local de pesquisa, por ser aquele no qual o meu interesse científico se intensificou e onde vi a possibilidade de desenvolvimento de um trabalho de qualidade, com as características que considero relevantes para o turismo. O segundo momento em que esse se torna meu "lugar" de pesquisa é aquele em que se estabelece a afetividade com o local, com a cultura e com a comunidade. Os moradores foram se tornando meus amigos, após a minha primeira visita, de tal forma que o local foi se tornando também um pouco meu. Assim, penso ter conseguido me aproximar e procuro apresentá-lo como um dos meus lugares, segundo a definição de Yázigi (2001), no texto A Alma do Lugar, em que esse autor define o lugar como sendo um local com alguma afinidade pessoal para você.

A primeira vez que ouvi falar de Laguna foi através de matérias em revistas de surfe. Nessas publicações, o local aparecia como um dos melhores 'picos' para a prática do surfe em ondas do Brasil, tornando-se, em minha imaginação, um paraíso do surfe em terras sulamericanas. A segunda vez que Laguna surgiu, agora como potencial local de pesquisa, foi já durante o mestrado, quando decidia qual seria o território escolhido para a aplicação das teorias estudadas.

O município de Laguna tem uma população total de 42 mil 138 habitantes (LAGUNA, 2014). Economicamente, o povoamento teve bases de constituição portuária, e em 1847, sendo nesse mesmo tempo promovido à cidade. Segundo o site do Município (LAGUNA, 2014), algumas características hidrográficas historicamente também facilitaram a escolha da localidade para povoamento pela coroa portuguesa, pela balneabilidade única no sul do país e a possibilidade de escoamento náutico de suprimento partindo do município.

As características culturais do município de Laguna têm suas bases também na sua estreita ligação com o mar e com o ambiente natural. A gastronomia e o artesanato típicos do local demonstram isso pelas suas características constitutivas, segundo Dall Agnol (2009). A autora descreve o artesanato típico do local, como uma renda de produção caseira artesanal, feita pelas mulheres de pescadores para a produção de redes de pesca e também de utensílios domésticos. Dall Agnol (2009) descreve os frutos do mar como fundamento das comidas típicas e, segundo, também a fécula de mandioca e a farinha de mandioca. 
O local pesquisado é o bairro do Farol de Santa Marta, mais especificamente três praias, aqui denominadas conforme a fala dos moradores. O Farol de Santa Marta é um bairro mais afastado, que não vem tendo o reconhecimento do município quanto ao seu potencial turístico. A Praia do Cardoso, uma das três praias do bairro, por exemplo, não é citada pelo site do município, apesar de todo o reconhecimento para o surfe nacional. O bairro fica localizado a mais ou menos 25 quilômetros do centro econômico do município, como demonstrado na figura a seguir.

Segundo Arantes e Santos (2010), a constituição do Bairro Farol de Santa Marta também tem seu povoamento a partir da pesca e da ligação cultural com o mar. Os autores afirmam que os primeiros moradores, após o faroleiro, foram os pescadores artesanais. Mesmo com a temporalidade e as dificuldades econômicas, essa atividade se mantém até a atualidade. Já as práticas turísticas, de trocas de serviços, são mais recentes e assumem características diferenciadas de acordo com o momento do ano, que envolvem aspectos sazonais, tanto da pesca quanto do turismo.

Apesar de não ter o reconhecimento para o turismo local, no entanto, a Praia do Cardoso para o surfe nacional recebeu, no ano de 2012, o Prêmio Greenish de maior onda surfada no Brasil, que todo ano premia a maior onda surfada e o melhor tubo. O surfista local, responsável pelo feito, é um dos entrevistados neste trabalho.

O surfe aparece como uma das práticas esportivas realizadas pelos turistas de Santa Catarina e é possível afirmar que o surfe tem sido uma prática, tanto de turismo, como prática esportiva pela importância que a localidade tem para o surfe nacional.

A metodologia escolhida para este trabalho tem orientação antropológica, o que implica na observação participante como técnica de pesquisa. Nesse sentido, é de extrema importância o que afirma Malinowsky (1978, p.21): “[...] o pesquisador deve, antes de mais nada, procurar afastar-se da companhia de outros homens brancos, mantendo-se assim em contato o mais íntimo possível com os nativos".

O conjunto de aspectos que se entrelaçam no objeto de estudo me levou à escolha por uma prática com a qual tenho forte vínculo. Tive como fatores motivacionais dessa escolha os princípios dos critérios de Malinowsky. Decorreu daí o meu olhar para as potencialidades das práticas turísticas desse local, segundo o olhar da sua comunidade, em função da minha vinculação em relação ao surfe e ao ambiente em que ele é praticado, considerando também a 
relevância do local para a prática desse esporte e para o turismo, e o fato de conhecer algumas pessoas do local.

Segundo Eduardo Yázigi (2001, p.24):

Alma são materialidades, práticas e representações com uma aura que se contrapõe ao que chamaríamos de 'desalmado'. Não creio que possa ser entendida por processos lógicos. Há alma quando há paixão das gentes pelo lugar. A alma orbita além da ciência, e tem de ser entendida num plano mais elevado que o formato acadêmico.

Em princípio, quero dar o meu entendimento e de que forma este foi aplicado a minha experiência.No momento em que entrei em contato com esse corpo, quando contrapus a minha cultura e os meus fazeres com os da localidade, através da minha experiência de campo, houve uma transformação, o local passou a ter alma. Acredito que essa personalidade do lugar seja o que eu entendo como a alma do mesmo e, a partir desse entendimento, posso dizer que este não é só um local, mas também, o lugar da minha pesquisa.

Segundo Eduardo Yázigi (2001, p.19), algumas localidades enfrentam o desafio de ultrapassar o “[...] difícil dilema de escolher entre cair na mesmice da globalização ou de buscar um caminho condizente com o diálogo, com raízes territoriais e culturais”. E complementando o que Yázigi diz, Krippendorf (2000) defende, em A Sociologia do Turismo, que a comunidade tem e deve ter o direito de decidir os caminhos do desenvolvimento do turismo. Sendo assim, o difícil dilema de Yázigi, de certa forma, se mostra com possibilidades de respostas a partir da comunidade, sendo essa resposta, ouvir da comunidade, da alma do lugar, suas escolhas e a forma como essa alma se enxerga.

Dessa forma, numa tentativa de apresentar a alma, o lugar e não só sua estrutura física, seu corpo, quero transcrever um pouco das minhas experiências e de como esse local passou a se transformar em um lugar. Igualmente, chama a atenção e procuro demonstrar aqui o quanto esse lugar nos apaixona, pelo tanto que a comunidade demonstra ser apaixonada por ele.

Meu primeiro contato, descrito em trechos tirados do meu diário de campo, é a epígrafe deste trabalho:

"Visite-me: a incerteza do fazer do pesquisador, ser colocado, em um ambiente adverso, culturalmente diferente do seu e completamente imerso em outra sociedade. É desesperador! Me vejo sentado, olhando para o mar, a praia mais linda que já tinha visto, possibilidades inúmeras, 
entretanto, o medo era tão grande... chorar diante da minha primeira visita, e, ao me "revisitar", perceber que essa desconstrução é então a porta de entrada da minha visita, e a reconstrução a chegada do meu primeiro visitante."

Antes de tudo, destaco o entendimento pessoal de que sempre me senti como um visitante daquilo que me desperta curiosidade. Durante toda a minha trajetória acadêmica, eu sou e sempre fui um visitante e um visitado, um visitante em relação ao que me provoca inquietações e um visitado daquilo que me acolhe nesse processo.

O Turismo sempre se mostrou para mim um 'caos', que se manifesta no estabelecer relações,que se descompõem após esses vínculos. Nesse sentido, é interessante considerar a fala de Trigo (2013, p.20): “[...] o medo é a parte da aventura, da descoberta. Desde os primórdios da história, o mistério foi parte inseparável da busca do conhecimento." Essa incerteza e curiosidade desestabilizantes há muito motivam a visita.

A epígrafe deste ensaio é também o momento mais representativo de desestabilidade e reconstrução, visita e visitação. Trata-se não da minha primeira ida ou da minha chegada a Laguna, ou mesmo ao Farol, e sim da minha primeira visita real como pesquisador, do momento em que a desestabilidade era inquietante e angustiante.

Pude perceber, em minha primeira visita a campo, em conversas com os moradores locais, que, dentro do mar, a relação entre surfistas locais e visitantes não tem grandes problemas. A logística de ordem nas ondas é sempre respeitada, e o morador local sabe da importância desse turista, sendo assim, uma relação harmoniosa. Eles destacaram, no entanto, a existência de conflitos e brigas, no mar, com aqueles que tinham uma casa de verão na praia. Segundo um deles, "eles vêm das cidades das redondezas e se acham locais [...] como não dependem da renda daqui, não respeitam os turistas nas ondas". Percebi, assim, que as características do local geram desdobramentos em sua descrição. Sendo assim, a partir dessa caracterização, busco a descrição e a apresentação dos desdobramentos desta relação como sendo o objetivo desta pesquisa. 


\section{Trama $^{4}$ de olhares teórico-metodológicos}

É necessária uma descrição da atividade turística nas Praias do Farol, segundo os múltiplos ‘olhares' envolvidos na pesquisa. Olhares esses sobre a prática turística, as formas com que ela se apresenta, e sobre como esses olhares se apresentam para mim. Nesse sentido, apresento uma possibilidade de olhar para o 'meu lugar' de uma forma diferente, o que pode ser esclarecedor quanto à forma como esse se apresenta para mim, mas também sinalizador para aspectos gerais dos olhares.

Transversalmente, as considerações apresentadas aqui direcionam-se para o reconhecimento de uma trama de olhares da comunidade, dos autores utilizados e meus, a partir desses, para as práticas da atividade turística na localidade, compreendendo o aspecto cultural do turismo local, segundo orientação da Antropologia no estudo do Turismo.

Segundo Gândara, Hack Neto e Manosso (2014, p.3-4), o Turismo não deve ser entendido apenas a partir de um olhar "[...] mas sim por um somatório de saberes necessários para o entendimento desta área de estudo.” Para Beni (2001), conceito de turismo é transdisciplinar e Multidisciplinar, e o entendimento do mesmo varia de acordo com a empregabilidade dos conceitos no contexto do estudo.

O turismo é uma combinação complexa de inter-relacionamentos entre produção e serviços, em cuja composição integram-se uma prática social com base cultural, com herança histórica, a um meio ambiente diverso, cartografia natural, relações sociais de hospitalidade, troca de informações interculturais. O somatório desta dinâmica sócio cultural gera um fenômeno, recheado de objetividade/subjetividade [...]. (MOESCH, 2002, p.9)

Quero deixar expressa aqui, entretanto, a forma como o meu olhar se dirige para a atividade e quais teorias o direcionaram nessa direção. Como deixo explícito no trecho acima, o crescimento econômico que o turismo traz é indiscutível, mas essa perspectiva não leva em consideração todas as vertentes e as possibilidades que o turismo tem. Em certo modo, esse crescimento pode também representar um crescimento social e uma preservação do ambiente

\footnotetext{
4 A expressão, aqui, está sendo utilizada no sentido das teorias apresentadas por Baptista (2014), para se referir à complexidade de atravessamentos no fenômeno estudado e também à multiplicidade de sujeitos envolvidos.
} 
natural; contudo, alguns estudos, não deixam claros os impactos que a atividade tem, principalmente na escala socioambiental.

$\mathrm{O}$ entendimento de turismo que apresento aqui tem como princípio não o seu viés econômico e, sim, suas possibilidades como gerador de fluxos, e como consequência desses fluxos, oportunidade de desenvolvimento para as comunidades onde este se instala. Partindo das possibilidades ligadas aos segmentos de Turismo de Sol e Praia, desenvolvi a pesquisa de acordo com a situação apresentada nas Praias do Farol.

A desterritorialização, como turista e pesquisador, foi o motor do desejo da minha viagem ao conhecimento de uma realidade cultural diferente. Posteriormente, com a tentativa de entendimento dessa realidade a partir do residente, houve também, uma mudança do meu território, lugar em que me sinto seguro em minha estrutura de poder, para um, onde então estou desterritorializado.

Esse ideal de desterritorialização, para além do sentido geográfico, é apresentado e um sentido subjetivo de saída da sua zona de conforto, propiciando viagens não só no contexto visível e, sim, no subjetivo. A sugestão é aqui entendida tanto no turismo como na pesquisa, de fato pesquisar aprender também é viajar dando uma possibilidade diferenciada do entendimento do Turismo. Para Baptista (2013, p.2-3):

Entende-se que não há como acionar saídas dos territórios, se não houver o reconhecimento do 'si mesmo' e a percepção clara da potência agenciadora de reinvenção de si, de autopoiese. Para 'seguir viagem', o turista tem que acreditar na potência de a viagem produzir prazer, processo entendido aqui como retorno do 'investimento desejante' produzido, através da obtenção de valores emocionais, racionais e materiais agregados, que compensem o 'movimento'.

Tive a experiência da curiosidade, de conhecer aquilo que me diferencia de outros sujeitos e de outras culturas, na fronteira de minha cultura com as da minha pesquisa. Essa desconstrução é que me constrói e me instiga, a curiosidade desestabilizante pelo outro inerente ao Turismo.

No caso do Farol, ao longo do período pesquisado, pude perceber que a comunidade considera e salienta como suas marcas culturais, a gastronomia na praia, ao lado dos pescadores e os restaurantes em barracões de pesca. Essas marcas são subjetivações que podem trazer benefícios. Além disso, demonstra-se a marca cultural do cuidado com a praia e com os turistas, 
se levarmos em consideração o envolvimento da comunidade local nas rotinas da praia, seja como bombeiros, com alugueis de prancha para turistas ou nos serviços de alimentação.

Porém, não estamos diante apenas de uma economia de signos nesse caso, mas também - se é que os dois termos podem ser separados — de uma intensa política de signos, de uma política da cultura. (HANNERZ, 2010 p.17).

É claro que um ganho econômico é do interesse dessas comunidades, mas a escolha e as motivações sobre de que forma esse ganho será obtido deve partir da comunidade e dos seus interesses. Decorre dessa percepção o entendimento dos desdobramentos e aproximações das fronteiras culturais no objeto de pesquisa, para que, então, esses interesses façam parte das possibilidades da atividade turística no lugar.

A estratégia metodológica, com o viés da Antropologia, se aproxima do meu jeito e da forma como produzo as interações com a realidade. Trata-se de um modo de 'entrar em contato'. Outro aspecto a ser considerado como sinalizador é o fato de que o turismo é uma atividade que possui, em sua dinâmica, a mudança e a saída do cotidiano. Sendo assim, a diferenciação proveniente de sua complexidade se estabelece justamente nas relações dos contatos dos seus fazeres, ou sua cultura com os fazeres e a cultura daquele que está no outro lado da fronteira. Nesse sentido, podemos entender que o Turismo se desenvolve na complexidade das relações estabelecidas, o que pode vir a interferir nas investigações a seu respeito. Em uma comunidade onde o Turismo é um fazer do cotidiano, para mim, a atividade se apresenta como a representação desses fazeres, ou seja, como cultura.

Dessa forma, entendo a aplicabilidade dos fazeres, ou o estudo do Turismo com possibilidades de entendimento e interpretação como cultura. Isso se verifica, já que, segundo Geertz :

[...] o homem é um animal amarrado a teias de significados que ele mesmo teceu, assumo a cultura como sendo essas teias e a sua análise; portanto, não como uma ciência experimental em busca de leis, mas como uma ciência interpretativa, a procura do significado. (GEERTZ, 1989, p.15). 
A Antropologia, segundo Geertz (1989), trata do estudo do outro; congruentemente, Turismo tem o conhecimento e a vontade pelo diferente como base para o interesse e a motivação de viagens. Segundo Burns e Holden (1995, apud BURNS, 2002, p.92),

A antropologia e o turismo (como um campo de conhecimento) apresentam uma sinergia óbvia. Ambos tentam identificar e entender a cultura e a dinâmica humana. Uma vez que o turismo é um conjunto global de atividades que cruza muitas culturas, precisamos de um conhecimento mais profundo sobre consequências da interação entre sociedade que geram e recebem turistas.

Esse trecho do trabalho de Burns (2002) demonstra a estruturação do pensamento, a partir do entendimento do desenvolvimento do turismo. Esse pensamento está posto através das relações estabelecidas com a prática da atividade. Acreditando nas suas especificidades culturais, pode-se entender o turismo como prática cultural.

A partir do reconhecimento do Turismo como fazer cultural, temos a possibilidade de estudá-lo com orientação antropológica, que Geertz (1989) diz ser a interpretação das culturas, possibilitando um entendimento da lógica social do outro. Acredito que esse entendimento da logística social nas relações estabelecidas com o Turismo pode permitir, também, a percepção de indicativos dos caminhos que a atividade vai seguir nas Praias do Farol segundo seus desdobramentos.

Entende-se, portanto, que Turismo e Antropologia são áreas interligadas, já que os antropólogos se debruçam sobre relações e fazeres culturais. Em alguns casos, a atividade turística se desenvolve.

Ainda para Geertz (1989), todo fazer é um texto passível de interpretação, e o papel do pesquisador é, assim, obter as interpretações desse texto para, então, fazer as suas, ou seja, ter o entendimento de uma cultura turística é, segundo suas concepções, fazer suas próprias inferências e interpretações.

Sendo essa identidade aquilo que a diferencia de outras culturas, é nessa concepção de cultura e fazer, que segundo Geertz (1989), esse estudo buscou o entendimento da subjetividade encontrada no lugar. Esse entendimento é necessário, se quisermos que haja o desenvolvimento das relações interacionistas estabelecidas com o turismo e seus contatos entre visitantes e visitados. 
Esse texto se modifica em estilo e entendimento ao longo do amadurecimento do entendimento da Ciência. Sua forma de pensar muda também sua forma de escrever, mesmo não invalidando as formas anteriores.

Para Clifford (2002, p. 35), “[...] ainda são apresentadas no modo experiencial, de métodos específicos, 'o eu estava lá' do etnógrafo como membro integrante e participante”. Esse eu estava lá, que Clifford defende, é o mesmo que Castrogiovanni defende como se reescrever a partir de um híbrido de sua própria cultura em contato com outra.

Ainda segundo Geertz (1989, p.20), o que o pesquisador enfrenta:

[...] é uma multiplicidade de estruturas conceptuais complexas, muitas delas sobrepostas ou amarradas umas às outras, que são simultaneamente estranhas, irregulares, e inexplícitas, e que ele tem que, de alguma forma, primeiro apreender e depois apresentar.

Segundo Geertz, (1989, p.19) “[...]A análise é, portanto, escolher entre as estruturas de significação". E assim, o que apresento são meus olhares a partir disso. É como narrativa que se inscreve aqui o dissertar deste pesquisador. Eu me inscrevo e reescrevo aqui, a partir dessa experiência, que me desestabilizou em contato com um mundo de conhecimentos novos, científicos e empíricos, na minha pesquisa.

Segundo o que diz Burns (2002), a comunidade tem sua contribuição para o entendimento das perspectivas sociais, auxiliando no sentido de evidenciar a necessidade dessas perspectivas para o Turismo. Na mesma perspectiva, estão as concepções de Krippendorf (2000), que mostra a importância de se pensar o social no desenvolvimento do Turismo.

A dimensão social neste trabalho considerou as manifestações culturais, conforme a expressão da própria comunidade. Essas manifestações foram buscadas no lugar de pesquisa, sendo elas os fazeres culturais propícios e intrínsecos na cultura turística que se desenvolve nas Praias do Farol. Esse típico, o diferente que identifica, que desperta curiosidade, é justamente o que leva a uma contribuição social da atividade para a comunidade.

A partir disso, basicamente os procedimentos de pesquisa foram a ida a campo por dois períodos, para observação direta e participante, passando um período interagindo com o fazer turístico. E mais, estabelecer relações com a comunidade local e os turistas, deixando claro o meu papel como pesquisador e as intenções da pesquisa. 
A opção pela Antropologia como orientação teórico-metodológica vai ao encontro dessas percepções e da aproximação com o entendimento da atividade a partir das Ciências Sociais. Além disso, a estratégia metodológica, com o viés da Antropologia, se aproxima do meu jeito e da forma como produzo as interações com a realidade. Trata-se de um modo de 'entrar em contato'. Portanto entendo a necessidade de um capitulo de apresentação sobre as técnicas empregadas para a produção da pesquisa de campo que esse estudo proporcionou, materiais e métodos utilizados que aqui denominei como 'o que fazer e como fazer' à ser apresentado ao longo do próximo capitulo.

\section{O que fazer como fazer}

Os fazeres desta pesquisa orientam-se segundo Malinowsky (1978), mas são apresentados numa escrita contemporânea, conforme Geertz (1989) e Clifford (2002), abordando temas do Turismo e da Hospitalidade. Este estudo foi construído, mais precisamente, na composição entre o olhar de um visitante sobre o entendimento do turismo local, por parte dos visitados, ou seja, da comunidade do Farol de Santa Marta SC

Sobre o entendimento da prática, aqui se procurou trabalhar segundo Eckert e Rocha (2008). As autoras defendem, em seu artigo, Etnografia Saberes e Práticas, fundamentalmente, como se procede normalmente uma etnografia, ainda que, como dito anteriormente, com o que se pretende neste estudo, não se acredita na possibilidade e adequação a se apegar a um único modelo. De qualquer forma, o conhecimento produzido e contatado pelos autores é sempre um norteador para o entendimento do estudo e para a prática da pesquisa que vai se construir no campo. Essa forma de fazer seria, segundo as crenças desse trabalho, a forma como se deve iniciar o desenvolvimento de uma pesquisa, norteando-a pelas técnicas antropológicas descritas.

Além disso, as autoras deixam claro que o pesquisador tem o papel de interpretar, segundo suas concepções, de dentro do contexto social do outro; porém, numa tentativa de minimizar suas interferências, tanto dele sobre o contexto quanto do contexto sobre ele mesmo, é necessário uma vigilância sobre sua epistemologia, entretanto, segundo as concepções de Clifford (2002), inevitavelmente, tal vigilância não anula a interferência do pesquisador. Basicamente os procedimentos de pesquisa foram a ida a campo por dois períodos, no mês de janeiro de 2014 e janeiro de 2015, nestes períodos foi feito, observação direta e participante, passando um período 
interagindo com o fazer turístico. E mais, se estabeleceu relações com a comunidade local e os turistas, deixando claro o meu papel como pesquisador e as intenções da pesquisa.

A preocupação desmedida do (a) pesquisador (a) com a estrutura de uma entrevista dirigida, quase transformado em questionário, e sua insistência no afastamento do entrevistado de uma reflexividade sobre suas situações de vida ordinária, em antropologia, pode conduzir o etnógrafo muitas vezes ao desencontro etnográfico e, até mesmo, ao desconforto do desinteresse por parte do grupo de investigação. Ao contrário, as relações de reciprocidade, mesmo que oscilantes em dias de pesquisa ditos mais produtivos e outros permeados de dificuldades de toda ordem (o informante que "deu bolo", a desconfiança de um entrevistado sobre a fidelidade de suas concepções, etc), são construídas em situações de entrevistas livres, abertas, semi-guiadas, repletas de trocas mútuas de conhecimento. (ECKERT, ROCHA, 2008, p. 14)

Além disso, a coleta de dados foi através de entrevistas não diretivas, e conversas informais gravadas e transcritas, sobre as quais foram feitas as inferências e as interpretações com bases nas teorias e no Turismo. Ainda, a pesquisa orientada na Antropologia tem, segundo as autoras, a possibilidade de interpretações e inferências a partir do diário e do caderno de campo. De fato, tais ferramentas técnicas têm papel primordial na descrição que aqui vos apresento.

Após cada mergulho no trabalho de campo, retornando ao seu cotidiano, o pesquisador necessita proceder a escrita de seus diários de campo. Os diários íntimos trazem farta bibliografia sobre os medos, os receios, os preconceitos, as dúvidas e as perturbações que o moveram no interior de uma cultura como forma de compreensão da sociedade por ele investigada. Trata-se de anotações diárias do que se vê e ouve entre as pessoas com que ele compartilha um certo tempo de suas vidas cotidianas (ECKERT, ROCHA, 2008, p.14-15).

Além desses procedimentos, as autoras ainda descrevem a utilização de outras ferramentas do fazer etnográfico, ferramentas estas que aqui também se propõem:

[...] o caderno de notas. É no caderno de notas de campo, onde o(a) antropólogo(a) costuma registrar dados, gráficos, anotações que resultam do convívio participante e da observação atenta do universo social onde está inserido e que pretende investigar; é o espaço onde situa o aspecto pessoal e intransferível de sua experiência direta em campo, os problemas de relações com o grupo pesquisado, as dificuldades de acesso a determinados temas e assuntos nas entrevistas e conversas realizadas, 
ou ainda, as indicações de formas de superação dos limites e dos conflitos por ele vividos. (ECKERT, ROCHA, 2008, p.15)

Essas técnicas são os procedimentos práticos que constituem esta pesquisa. Por se constituir em uma pesquisa com orientação antropológica, é importante ressaltar que a experiência da pesquisa pode e deve trazer demandas modificadoras dessas técnicas e ou acrescentar novas técnicas as descritas, devendo ser revistas a todo o momento, durante a pesquisa de campo e o processo de interpretação.

\section{Síntese da trama}

Com isso, é possível, em analogia com o surfe, resgatar as melhores ondas surfadas na série, reapresentando os melhores momentos de fala, explicados segundo as escolhas teóricas, finalizando em uma síntese da trama entre as teorias e a pesquisa empírica, trama essa entendida a partir de Baptista (2014).

$\mathrm{O}$ entendimento da pesquisa proposta, exposta até aqui, tem como fundamento a compreensão de que a possibilidade dessa experiência, por ser única enquanto experiência, necessita de uma estratégia textual diferenciada para que seja apresentada. Possibilidade alcançada, segundo Clifford (2002, p.55), com "uma utopia de autoria plural que atribui aos colaboradores não apenas status de enunciadores independentes, mas escritores [...]”.

Além disso, segundo a proposição teórica desse mesmo autor, o que busquei apresentar aqui foi a experiência do campo como ela se apresenta, apresentar o campo segundo o que o campo apresenta, de modo que os trechos de entrevistas apresentados, que foram gravados no campo e transcritos, são descritos, analisados e apresentados em trechos, não por não considerar importante a analise de cada uma das falas, e sim por considerar importante o contexto do assunto, e do contexto como um todo, priorizando toda à situação e não falas soltas ou mesmo descontextualizadas.

Para tanto, acredito ser de extrema relevância a identificação desses 'coautores'. Sendo assim, aqui trago os dados baseados no meu diário de campo, em que tenho como anotação como eles se apresentaram para mim, explicitando a motivação e a importância da escolha deles como sujeitos dessa pesquisa:

- A família de pescadores: seu Adilson e seus filhos, Adilton e Rafael. 
Seu Adilton é um senhor pescador antigo na comunidade do Farol de Santa Marta. Viveu ali, saiu e voltou novamente. Viu diversas transformações no Farol, entre elas a escassez de peixe por conta da pesca industrial, e a reconstituição da pesca artesanal com o crescimento do turismo. Viu o princípio das trocas entre culturas, a chegada do surf e do turista e com isso percebeu e pode aproveitar as oportunidades com o turismo, juntamente com seus filhos Adilton e Rafael. O fato é que o restaurante demonstra uma reorganização cultural sazonal, de acordo com as demandas do turismo e da pesca, e a forte cultura ligada ao mar.

\section{- Rafael "Faísca"}

Surfista local, ele representa o meu primeiro contato com os surfistas locais e foi porta de entrada para os meus contatos seguintes com outros. Rafael Faísca ganhou, no ano de 2012, no Cardoso, um prêmio de maior onda surfada. Conhecê-lo foi uma grande oportunidade, que me proporcionou extrema confiança nas informações sobre as praias. Ele me contou como ele viu o desenrolar da 'onda' que foi o Turismo na relação de trocas entre os pescadores e os surfistas.

- Katy e João

Em busca da vivência de ver isso de perto, busquei as trocas como forma de permanecer imerso nessa cultura, e fui bem recebido na Pousada Baiuka, onde João e Katyuscia (Katy), donos do estabelecimento, me receberam. Em troca de serviço no restaurante e na pousada, me oportunizaram o vivenciar o contato com o turista. Assim, aos poucos, fui percebendo como eles, como comunidade, lidavam com o entendimento sobre o desenvolvimento do Turismo na localidade.

$\mathrm{Na}$ sequência deste texto, apresento o relato do que encontrei em campo, valorizando o olhar deles e os desdobramentos das relações estabelecidas na cultura turística local.

No campo, uma onda que se mostrou forte e que interfere no turismo e no modo como a atividade se desenvolve é a cultura da comunidade local, entendendo cultura, segundo Geertz (1989) como os fazeres da comunidade local. Os moradores que não passam todo o ano no local não têm ideia da dimensão e da importância das práticas do Turismo e da pesca, no cotidiano e nos fazeres, ou seja, na cultura da comunidade local. Eles também não levam em conta essa cultura para o rendimento e a manutenção da atividade do Turismo de Sol e Praia.

Katy: Áí vamo ser igual, eles aí vai perdendo a essência, vai perdendo até, é cultura, na verdade, é como se fosse cultura, por que, se tem quinze restaurantes, os quinze servem a mesma coisa, do mesmo procedimento, ninguém tem anchova na brasa, todo mundo tem anchova grelhada ou 
frita em postas fritas, filé filé a milanesa é filé grelhado ninguém faz molho de maracujá, molho de mostarda, ninguém tem...

A hospitalidade e o bem receber, bem como a qualidade, no que definem ser o modo do Turismo na localidade pensado segundo Camargo (2008), são aspectos pautados pela relação com a pesca e com os pescadores como cultura, entendida segundo Geertz (1989). Nesse caso, estão presentes, desde o princípio da atividade, como podemos ver no trecho de fala destacado:

Adilson: [...] vamo fazer um restaurantezinho pra nóis, um restaurante pra nóis, servir o turismo, e o turismo quer, que que o turismo queria, o turismo queria um peixe fresquinho, que o pessoal da cidade come aqui o peixe congelado do mercado né e não sai satisfeito né, o peixe congelado do mercado, ...

E como Arantes e Santos (2010) descrevem em seu estudo, as atividade do turismo na localidade se caracterizam com interesse nos fins econômicos e base na sazonalidade da pesca artesanal e do turismo, adquirindo forma de acordo com a época do ano em uma logística simples e funcional.

Adilton: [...] a gente foi crescendo assim, meio no no verão trabaia com o turismo e no inverno a gente pesca...

Katy: [...] o turismo começou com mais simplicidade e menas ambição $\operatorname{assim} . .$.

A dádiva de Marcel Mauss (2002) encontrei como uma relação natural estabelecida na cultura turística das praias e as culturas do surf e da pesca. Tudo isso representa, segundo a concepção de hospitalidade aqui trabalhada, o objetivo de caracterizar as atividades turísticas nas Praias do Farol. Uma das características é a troca da hospitalidade que eles mesmos descrevem nos trechos destacados:

Adilton: [...] o povo gosta do farol por causo disso né, olha só aquele casal que tá ali ali. Ele veio semana passada aqui né Rafa. Aí veio ali pediu um camarãozinho, daí viu o prato da anchova passar aí veio esse final de semana comer, é assim que funciona né.

[...] ]eu acho que nóis subemo agradar mais do que chega aqui, do que a gente quando sai não é tão agradado entende?

Faísca: É que, tipo assim ó, o povo humilde assim né, tem muita fé, tá ligado? Tem muita fé na parada e porra muito receptivo, assim.

Renan: Tu acha que isso influencia positivamente no turismo?

Faísca: Influencia cara, influencia.

João: Faz a pessoa sair de longe e vim pra cá, a hospitalidade das pessoas aqui eu acho que é também, é legal. 
Essa relação de trocas pode ser boa, mas também representa múltiplos contatos e, como todo contato, imbricado de representações e de conflitos, esses apresentados no trecho a seguir se estendem para as trocas entre as culturas. Acredito que a relação entre visitantes e visitados pode ter seu lado positivo, mas também seu lado negativo nessas trocas (BURNS, 2002):

Faísca: [...] tem assim ó do pescador artesanal com o pescador industrial, é um conflito, o outro conflito é pescador com o turista, que o pescador não gosta do turista...

Adilson: [...] não quer saber, não deixa da o, fecha o ciclo, a nossa rede aqui é malha onze, onze centímetro, peixe de dois quilo e meio três quilo, então aquele peixe ali ele já cresceu , já ficou adulto, desovou [...] já reproduziu, pa depois nois pega, agora os barco grandão, os trainhero os barco de arrasto industrial, a malha deles e malha dois e meio dois dai tu e a diferença...

Rafael: O que a gente não quer é stress com turismo né, a gente não que né, a gente tá vendo né que a coisa tá mudando né , pa turismo também , não é só pesca é pa turismo também né, e a gente não quer stress com eles né, o que a gente quer é conversar com eles é ver opiniões né conversa, e a gente acha legal isso e e não pode fazer isso, eu acho assim, inclusive até na na no verão agora, eu e ele aqui ainda brigemo com os nativo daqui por causa que eles quiriam o né tira o turismo da, brigando no mar por causa de onda, isso ai nós achemo errado né, nos somo contra isso ai.

Faísca: [...] não é assim ó é pessoal que mora na região, por exemplo, criciúma, e tubarão e, dai se acha do lugar assim mas do que, ta ligado bota o outro pra correr e é muito doido por que o pessoal daqui é super passivo entendesse, de boa pá, por que por que aluga casa, por que, claro tem uns cara de criciúma que po chega ai e querem botar banca dai a galera é obrigada a po, não quem é dia é a gente, mas no mais assim é tranquilo cara...

Katy: [...] tava aqui, era mulher que tava surfando, e o pessoal xingo ela, chamaram ela de filha da puta, e tal, ai ela saiu chorando, ai o como o pessoal tava hospedado aqui acabaram nos contando...

Esses desdobramentos característicos da descrição, feita anteriormente, culminam em problemas e em possibilidade de resolução, partindo da comunidade. O problema enfrentado com o localismo ilustra o que Krippendorf (2000) e Barreto (2003) se referem com a comunidade se pronunciar sobre seus desejos quanto ao turismo.

Segundo Castrogiovanni (2003), a comunidade é a primeira a aceitar e a tomar posse desse turismo. Nas Praias do Farol, eles entendem suas práticas como cultura, como uma manifestação de seus fazeres, que eles têm interesse que se mantenham e medo de que isso não 
aconteça. Essa cultura turística local aparece em aproximação com o estilo de vida do surfe, o cuidado com o local e a preservação das relações com a natureza.

João:[...] É assim a gente, particularmente, nois, a gente gosta de ver ter as coisas limpas né, e se a gente que é daqui não tomar a iniciativa e esperar pelos órgãos né é complicado por que, a prefeitura aqui ela é muito negligente cara, muito assim e também, é o povo daqui também teria que se unir mais, [...] então a gente já tá nessa, a gente já fez vários quatro cinco sei mutirões eu acho, no decorrer ai e...

João: É eu acho que pro futuro, o meu maior medo é a parte, dos órgãos né, principalmente prefeitura cara por que, é não só aqui né o Brasil é é corrupto cara então, então a lei é de quem tem dinheiro né, quem obedece a lei é o pobre que não tem dinheiro pra fazer e ir lá e comprar mas quem tem dinheiro, faz prédio onde não pode, desmata onde não deve e esse é meu maior medo é vim aqui as grandes empresários e quere mete um resort fecha a praia pra eles.

Katy: Eu acho que o nosso maior desafio, talvez seja o que o Farol perder a essência de hoje que é restaurante de forma formato de casa, que era casa e abriram os as repartições e virou restaurante, ...

É primordial o entendimento de que o turista traz benefícios para a comunidade local, e essa comunidade cresce com o dinheiro desse turista e se mantém com uma boa autoestima, quando há valorização desse turista para as suas práticas. Contudo, o veranista não percebe essa importância, por não ter a mesma necessidade, não tendo, assim, a mesma hospitalidade pautada na dádiva que a comunidade local.

O veranista, ou morador de segunda residência, não precisa desse turista e não recebe nada dele, a não ser lotação ou 'crowd' (mar cheio para os surfistas). Ele tem suas necessidades econômicas supridas na sua cidade. Sendo assim, nem eles têm interesse em trocar experiências com o turista e nem o turista tem interesse em ter experiências com eles. Essa situação tem que ser gerenciada por especialistas e controlada pela comunidade local. É necessária uma intensificação do localismo da comunidade, para uma diminuição do localismo de segunda residência.

Vemos que, algumas vezes, a gestão não traz ferramentas para o desenvolvimento dessa preservação, mas acredito que o Localismo possa ser um dispositivo para isso. Nesse sentido, é importante entender a educação patrimonial como parte de uma prática cultural que preserve o patrimônio local. É possível que esse localismo do surfe e esse estilo de vida seja transportado, 
em um planejamento que preserve as práticas turísticas e a própria cultura turística nas Praias do Farol.

\section{Considerações finais}

Por tanto, buscando entendimento e responder aos objetivos propostos no início de pesquisa, como resultado das características das práticas turísticas nas Praias do Farol, foi encontrado e apresentado, segundo seus residentes, uma diversidade de olhares. Para além da caracterização física das Praias do Farol, busquei o subjetivo do que o lugar me apresentava. Dessa forma, segundo Geertz (1989), pude compreender que a vida em sociedade lá segue padrões representados por seus fazeres, fazeres esses que o autor denomina como cultura, os fazeres principais característicos encontrados são: a pesca, o turismo, e o surfe.

Outras formas de cultura são também marcas das características culturais das Praias do Farol; entretanto, as que se apresentam nas práticas turísticas são essas. Ainda é representativo das características que esses fazeres seguem padrões sazonais, sendo a pesca, em um determinado período do ano, e o turismo, como prática em outro período. Ressalto, também, o que defino como cultura de prática do surfe, que está transversal tanto nos fazeres da pesca quanto nos fazeres turísticos, mesmo que esses não sejam todos pescadores, por exemplo, é possível ver em seus fazeres características da cultura surfe.

Quanto às relações estabelecidas entre os turistas e a comunidade, ao que pude perceber, tem um princípio básico, que teoricamente descrevi como hospitalidade. Para Marcel Mauss (2002), existem implicitamente, contratos sociais estabelecidos, baseados no Dar, Receber e Retribuir, um sistema de trocas que se replica de acordo com as práticas culturais de cada comunidade.

Dessas relações estabelecidas, a partir das características das Praias do Farol, emergem desdobramentos, segundo sua comunidade, e, ao mesmo tempo, medos e incertezas, com relação à forma como o turismo vai continuar na localidade. A verdade é que uma cultura turística traz características de autopreservação, para que ela se mantenha como foi desde a sua implantação. O medo com relação ao planejamento da atividade, com relação à perda de suas características originais e do seu negócio, é proveniente dos desdobramentos das relações da atividade.

Segundo seus residentes, o maior medo é que, com os desdobramentos dessas relações, a cultura turística do local se perca. A marca desse medo é também um dos desdobramentos das 
características relações estabelecidas lá. Existem atitudes preservacionistas, por parte da comunidade, para com aquilo que consideram como patrimônio que construíram ao longo desse crescimento recente do turismo. O localismo foi apresentado como uma situação de cuidado do surfe, que transversalmente se assemelha às situações que esses desdobramentos, como, por exemplo, os mutirões só de locais para um cuidado com as Praias do Farol, envolvendo práticas de recolhimento de lixo e pedidos junto ao poder público.

Depois dessas considerações, finalizo esta viagem investigativa, sabendo que não há como contar a totalidade do processo de aprendizagem. Contei o que me contaram, aprendi a olhar com os olhos que olharam e no cruzamento desses olhares, com os saberes dos autores, também tive meu olhar transformado, tanto nas praias do Farol, quanto nas 'praias do conhecimento acadêmico'. Nos dois casos, as ondas são fortes e desafiadoras, mas valem o risco.

\section{Referências}

SANTOS, R. J.; ARANTES, E. M.. Turismo e dinâmica cultural em uma comunidade de pescadores artesanais: o caso do farol de Santa Marta em Laguna (SC). Revista Brasileira de Pesquisa em Turismo, v. 4, n. 1, 2010.

BAPTISTA, M. L. C.. Quem é o Sujeito da Comunicação. In: A proposição de sujeito-trama, como campo caosmótico, e suas imbricações complexas, em tempos de internacionalização. In: COLÓQUIO BRASIL-ESTADOS UNIDOS DE CIÊNCIAS DA COMUNICAÇÃO $6^{\circ}$, CONGRESSO BRASILEIRO DE CIÊNCIAS DA COMUNICAÇÃO $38^{\circ} .2014$.

Baptista, M. L.. Desterritorialização Desejante em Turismo e Comunicação: Traços Especulares e de Autopoiese Inscriacional. XIV CONGRESSO DE CIÊNCIAS DA COMUNICAÇÃO DA REGIÃO SUL. Santa Cruz do Sul: Intercom/UNISC, 2013.

Baptista, M. L.. Quem é o Sujeito da Comunicação? A proposição de sujeito-trama, como campo caosmótico, e suas imbricações complexas, em tempos de internacionalização. VI COLÓQUIO BRASIL-ESTADOS UNIDOS DE CIÊNCIAS DA COMUNICAÇÃO - XXXVII CONGRESSO BRASILEIRO DE CIÊNCIAS DA COMUNICAÇÃO (p. 01-13). Foz do Iguaçu: Anais Intercom 2014.

Barreto, M.. Turismo e Legado Cultural: as possibilidades do planejamento. São Paulo: Papirus, 2003.

Beni, M. C.. Análise estrutural do turismo. São Paulo: Senac 2001. 
BURNS, P. M.Turismo e Antropologia: Uma Introdução. São Paulo: Chronos, 2002. 208p.

CAMARGO, L. O. L.. A Pesquisa em Hospitalidade. Revista Hospitalidade, S.1., v. , n. 2, p.1551, dez. 2008. Disponível em: <http://revistas.univerciencia.org/turismo/index.php/hospitalidade/article/view/151/176>. Acesso em: 25 nov. 2016.

CASTROGIOVANNI, A. C.. Turismo X Espaço: reflexões necessárias na pós modernidade. In: Gastal, S.; CAStrogiovanni, A. C.. Turismo na Pós modernidade (des)inquietações. Porto Alegre: Edipucrs, 2003. p. 43-50.

CLIFFORD, J.. A experiência etnográfica: antropologia e literatura no século XX. Rio de Janeiro: Editora UFRJ, 2002.

DALL'AGNOL, S.. Laguna como destino turístico: o pensar dos residentes. 2009. 145 pág. Dissertação. Programa de Pós Graduação em Turismo UCS. Caxias do Sul. 2009.

GÂNDARA, J. M. G.; NETO, E. H.; MANOSSO, F. C.. Percepções Turísticas: Como a Comunidade Local Representa e Simboliza o Destino Foz do Iguaçu-PR?. SEMINÁRIO DA ASSOCIAÇÃO NACIONAL PESQUISA E PÓS-GRADUAÇÃO EM TURISMO. São Paulo: ALEPH, 2014.

GEERTZ, C.. A Interpretação das Culturas. Rio de Janeiro: Guanabara Koogam, 1989. HANNERZ, Ulf. FLUXOS, FRONTEIRAS, HÍBRIDOS: PALAVRAS-CHAVE DA ANTROPOlOGIA TRANSNACIONAL. Cadernos Naui, Florianópolis, v. 1, n. 3, p.7-39, set. 2010. Disponível em: <http://naui.ufsc.br/files/2010/09/Hannerz_Fluxos-fronteirashíbridos.pdf>. Acesso em: 1 dez. 2016.

KRIPPENDORF, J.. Sociologia do turismo: para uma nova compreensão do lazer e das viagens. São Paulo: ALEPH, 2000.

Laguna, Prefeitura Municipal. Disponível em: <http://www.laguna.sc.gov.br/pontosturisticos.php> Acesso em: 02 dez. 2016.

MALINOWSKI, B. K.. Argonautas do Pacifico Ocidental:um relato do empreendimento e da aventura dos nativos nos arquipélagos da Nova Guiné melanésia. 2. ed. São Paulo : Abril Cultural, 1978.

MAUSS, M.. Sociologia e Antropologia. São Paulo: Cosac \& Naify, 2002. 
MOESCH, M. M..A produção do saber turístico (2. ed.) . São Paulo: Contexto, 2002.

TRIGO, L. G. G.. A Viagem: Caminho e Experiência. São Paulo: Aleph, 2013.

YÁZIGI, E.. A Alma do Lugar. São Paulo: Contexto, 2001.

Artigo recebido em: 03/12/2016

Avaliado em: 07/04/2017

Aprovado em: 15/12/2017 